\title{
ABSTRACT
}

When planned coherently, urban green spaces have the potential to provide cities with a range of unique ecosystem services that support ecosystem and human health. This paper draws on existing green space planning literature to argue that the integration of community gardens into standardised and previously under-utilised public park landscapes represents an innovative approach to providing ecosystem services. Particular focus is given to the challenges facing green space planning in Perth, Western Australia. At an individual level, community gardens provide a venue for an alternative and more accessible form of physical activity - gardening - and a restorative park environment that is a more attractive destination for neighbourhood walking. At the community level, gardens can facilitate bridging interactions between different social groups, whilst providing opportunities for local residents to participate actively in green space planning processes. Perhaps most importantly, community gardens can provide unique opportunities for environmental education that lead to enhanced local ecological outcomes. The paper concludes with a brief overview of the main challenges likely to be faced with this integration, and some strategies that may allow them to be overcome. It is hoped this paper will provide a background for future case studies, and a catalyst for increasing integration between formal green space planning and community garden development.

Keywords: environmental education; extinction of experience; planning standards; public participation; urban green space. 
"One of the first and universally acknowledged preconditions for happiness is living in close

4

7 Urban green spaces are essential components of $21^{\text {st }}$ century cities (Husqvarna Group, 2012).

8 They represent areas consisting primarily of unsealed and permeable surfaces such as soil and

9 vegetation; ranging from recreational landscapes, such as neighbourhood parks and playing

10 fields, through to gardens and semi-natural habitats such as wetlands and woodlands

11 (Swanwick et al., 2003). When planned coherently (i.e. as green infrastructure) these landscapes have unique and simultaneous potential to promote ecosystem and human health (Tzoulas et al., 2007). To better realise this potential, particularly in contexts of rapid population growth, recent initiatives have sought to integrate the many perspectives of urban green spaces into a single research agenda (James et al., 2009).

One particularly promising approach to the study of urban green spaces is ecosystem services, which Costanza and others define as the benefits that humans derive, either directly or indirectly, from the functioning of healthy ecosystems (Costanza et al., 1998). This concept represents a fundamentally ecological approach to green space planning based on the widely acknowledged assumption that physical and mental health and wellbeing are reliant upon functional natural environments (Millenium Ecosystem Assessment, 2005). It also represents an attempt to quantify the services that ecological systems provide, so that they can be given more weight in future policy decisions (Costanza et al., 1998).

The concept of ecosystem services is not without its potential challenges and disadvantages. For example, it may encourage an economic or utilitarian view of nature 
2 Nonetheless, this concept is increasingly acknowledged in urban green space research

3 (Bolund \& Hunhammar 1999; Elmqvist et al., 2004; Ernstson et al., 2008; Niemelä et al., 4 2010).

5

6

7

8

\section{Context of Paper}

In this paper, we explore the potential that integrating the planning and development of two distinct and hitherto largely independent forms of green space in urban areas - public parks and community gardens - has for for providing ecosystem services to urban communities. A broad review of the international literature is provided, with particular reference to the challenges facing green space planning in Perth, Western Australia. We begin with a brief background survey of public parks and community gardens research, including the relevant benefits and limitations of each. Specific examples are then provided of the potential for community gardens, particularly those with high degrees of public access and governed by local residents, to enhance the ability of under-utilised public parks to provide key ecosystem services. We conclude by considering some of the challenges to this integration, and some strategies for overcoming them.

\section{Public parks}

Both public parks and community gardens face unique opportunities and challenges in their ability to provide ecosystem services to urban communities. In the United States, parks have undergone numerous planning and design phases in the face of multiple changes in social circumstances since their origins during the industrial revolution, and yet they have remained a constant form of urban green space (Cranz \& Boland, 2004). This longevity can be attributed largely to the formalisation of park planning that occurred internationally during the middle decades of the $20^{\text {th }}$ century. This shift occurred in response to waning public 
support and enthusiasm for parks during the Great Depression followed by the devastation of WWII (Harnik, 2010). The reaction of planners was to provide parkland through standardised approaches, whereby both the quantity (e.g. hectares/person) and quality (e.g. playing fields/person) of parkland were determined through mathematical formulae. Standards continue to be the most common mechanism for determining green space provision in Australia (Veal, 2008; Byrne et al., 2010).

While their formality has proved an effective mechanism for securing sufficient quantities of green space, standards approaches have significant limitations. For example, they have received considerable criticism in terms of their ability to ensure good quality parkland that reflects the diverse needs of communities (Veal, 2008; Byrne et al., 2010).

These strengths and limitations can be seen in Perth, where standards approaches have been in place since the implementation in 1955 of the Stephenson-Hepburn Metropolitan Regional Plan (S-H Plan) (Stephenson \& Hepburn, 1955). Based on typical population densities, the S-H Plan prescribed a standard amount of public open space (parks) per person that translated in practice to at least 10 per cent of every new subdivision being devoted to public parks. This ' 10 per cent rule' continues to apply to new developments (Grose, 2009). The Perth metropolitan area will continue to experience significant outer suburban sprawl to accommodate a predicted population increase of half a million people ( 35 - 40 per cent $)$ over the next 20 years (Western Australian Planning Commission, 2010). Such prescriptions are crucial to ensure that adequate quantities of parkland are provided in these developing areas. Yet such a prescriptive approach does not necessarily ensure adequate quality of parkland. Of this 10 per cent allocation, the S-H Plan further prescribed that 85 per cent should be provided for the primary purpose of formal active recreation such as organised sport (Stephenson \& Hepburn, 1955). As a result, parkland within suburbs planned soon after the release of the S-H Plan has been characterised as monotonous, with limited leisure 
1 potential beyond sport and active recreation (Grose, 2009; see Fig. 1). Despite recent shifts

2 away from active recreation, local park planning still shows little sensitivity to local

3 ecological conditions, which is concerning given that Perth lies within a global 'Hot Spot' of

4 biodiversity (Grose, 2009). This example illustrates that planning standards can be largely out

5 of step with local social and ecological needs.

6 (INSERT FIGURE 1 HERE PLEASE)

7

8 Community gardens

9 In recent decades, community gardens have grown rapidly in prominence across many

10 Western nations, notably North America (Guitart et al., 2012). Far from being simply a public space in which to garden, they are unique public green spaces in their own right.

12 Community gardens have been created with a variety of underlying motives: not simply the opportunity to grow plants for nutrition and economic benefit, but also to satisfy local needs for contact with nature, education, civic activism and neighbourhood renewal (Lawson, 2005; Hou et al., 2009). Importantly for this paper, many community gardens also represent a citizen-led movement against the perceived failure of decision makers to provide appropriate open spaces (Francis, 1989). Thus, these gardens often incorporate a variety of non-gardening elements including lawns, social areas and spaces for active ball games. Such features effectively enable community gardens to function as small parks in their own right (Francis, 1989; Lawson, 2005). In this sense, they represent a type of public green space created outside of traditional formal planning structures, initiated by the efforts of local residents, and more reflective of a community's specific green space needs.

Although this position outside of formal planning processes has its benefits, it can also threaten the long-term survival of these often highly valued spaces. Lawson (2004), for example, concludes that planners have rarely given urban community gardens the same level 
1 of attention as permanent public spaces in the same way as parks, often resulting in

2 opportunistic land securement. This raises issues for future land allocation in high-density

3 developments, where land-use negotiations are already contested. Even established

4 community gardens face uncertain futures, with insecurity of land tenure identified as one of

5 the main challenges faced by their members (Guitart et al., 2012).

6

$7 \quad$ A case for integration

8 Against this background, there are obvious benefits to be gained from linking the creation

9 and management of community gardens with formal green space planning. As well as

10 providing community gardens with a secure spatial location within increasingly complex

11 urban land-use negotiations, Harnik (2010) argues that this link would provide the gardens

12 with much-needed formal planning approval and associated protection. This paper focuses on

13 an alternative perspective: namely, the potential for community gardens with high degrees of

14 public access governed by local residents to enhance the ability of certain public parks to

15 facilitate ecosystem services.

As public green space landscapes, community gardens have the potential to bring new

17 life to under-utilised park landscapes. The ability to transform under-utilised urban land has been fundamental to the recent resurgence of community gardens: for example, the vacant lot community gardens that grew in New York neighbourhoods in the midst of social decay during the 1970s (Lawson, 2005). This potential can be transferred into public land, with most cities having underused areas of parkland that could be put to better use as gardens

22 (Harnik, 2010). For example, community gardens have been used successfully to activate degraded 'internal reserves' that characterise the green space provision of many older Australian suburbs planned under Garden Cities principles (Freestone \& Nichols, 2004). 
As green spaces created and managed by local residents, community gardens also

2 have the potential to engage citizens in the governance of their local park. Rather than relying

3 solely on the decisions of governments and experts, there have been calls for modes of

4 sustainable urban growth that "spring from below" through the active engagement and

5 experimentation of citizens (Bendt et al., 2013, p. 28). Community gardens are good

6 examples of such bottom-up green space planning, where the creation and on-going survival

7 of these spaces are often determined by the actions and commitment of residents who use

8 these spaces (Hou et al., 2009; Rosol 2010).

The value of each of these attributes - to revitalise under-utilised land and engage

residents in green space governance - can be demonstrated in Perth. Despite planning shifts away away from a primary focus on active recreation, a large proportion of existing Perth suburbs retain poor quality parkland (Grose, 2009). Moreover, local residents remain largely excluded from current park planning processes, with the developers of new residential subdivisions primarily responsible for park design and creation before they are handed over to Local Government for on-going management (Carter, 2011).

Using the theoretical framework of ecosystem services, this paper argues that the integration of community gardens into public parkland can address both these limitations: directly, by providing a more attractive green space destination; and indirectly, by fostering opportunities for residents to become more involved in park planning processes. The following sections discuss in more detail how community gardens can enhance the ability of public parks to provide a range of key ecosystem services to local communities, using specific examples from Perth. 
1 Ecosystem services have been discussed using a range of different frameworks. One notable

2 and particularly relevant framework is outlined in the Millennium Ecosystem Assessment,

3 which classifies ecosystem services as provisioning, regulating, cultural or supporting

4 services (Millennium Ecosystem Assessment, 2005). More recently, Niemelä and colleagues

5 (2010) have classified the services specifically provided by urban green spaces into

6 provisioning (material benefits, such as food, fresh water and timber), regulating (regulation

7 of ecological processes upon which other services are reliant) and cultural (immaterial

8 services such as recreation, health benefits and education). It is the contention of this paper

9 that community gardens can enhance the ability of public parks to provide services from all

10 of these categories.

As public green spaces, the ability to provide services relating to agriculture and food production is relatively unique to community gardens. Opportunities to grow food in community gardens can contribute to healthier and more sustainable food choices in individuals, while addressing many concerns relating to food security and the maintenance of traditional agricultural systems (Evers \& Hodgson 2011). Local food production also has economic outcomes, which is of particularly value in low socioeconomic status areas (Dunn, 17 2010).

Community gardens can also contribute to numerous regulatory environmental services. A review of the benefits of domestic gardens noted their potential for providing localised air cooling, flood mitigation through rainwater interception and infiltration, and biodiversity havens for many bird and insect species (Cameron et al. 2012). These findings match those in Okvat and Zautra's (2011) review of the specific environmental benefits of community gardens. Community gardens can therefore contribute the ecological services that urban garden infrastructure provide, with this contribution more significant in high-density areas. 
2 be significant, particularly if they were to become more widespread in low socioeconomic

3 and high-density urban areas, this paper focuses on the range of cultural ecosystem services

4 that community gardens might provide to users of public parks. These are outlined in the

5 following sections.

6

$7 \quad$ Individual Health Services

$8 \quad$ Physical Activity

9 The potential for green spaces to improve the health of local residents has been widely

10 investigated, most commonly with reference to increasing physical activity. In their review of the numerous studies investigating the relationship between green space and physical activity, Lachowycz and Jones (2011) found conclusions to be inconsistent and mixed.

Nevertheless, they state that several studies found evidence of this relationship varying as a result of factors such as different qualities of green space and the demographic characteristics of the study group (age, socioeconomic status). We suggest that community gardens may be one form of green space capable of increasing physical activity for demographic groups not typically catered for by standardised park design. More specifically, we discuss how community gardens can enhance the ability of such parks to increase physical activity through the two pathways suggested by Bird (2004): first, directly as an attractive venue for exercise in a natural setting; and second, indirectly as a destination for forms of active transport such as walking.

While gardening has been found to be a particularly valuable form of exercise for older residents (Kingsley et al., 2009; Van Den Berg et al., 2010), it also has the potential to present an effective and accessible form of physical activity across communities. Bird (2004) suggests that gardening activity can increase upper body strength (in a way that alternatives 
1 such as walking or cycling do not) whilst being more accessible than popular pursuits such as

2 competitive sport might be to those with lower fitness levels. He further suggests that

3 activities such as gardening, where engagement in physical activity is secondary to other

4 outcomes, are likely to represent more sustainable forms of exercise (Bird 2004). By

5 providing opportunities to garden, community gardens may therefore present attractive green

6 space venues for engaging in physical activity for a wider demographic.

Walking represents one of the most effective forms of recreation for increasing

8 physical activity (Bird, 2004). Given that walking is one of the most popular forms of

9 physical activity in Australia, several recent studies have considered how neighbourhood

10 walking might be increased through the planning of local green spaces (cf. Giles-Corti et al.,

11 2005; Sugiyama et al., 2010). These studies suggest that large, attractive parks are most likely

12 to encourage neighbourhood walking, particularly in older residents. Whilst parks designed

13 for organised sport are often large, the flat and featureless nature of playing fields is unlikely

14 to make them sufficiently attractive to many non-sporting users. However, with thoughtful

15 re-design, new features could be added to these parks to make them more attractive to a wider

variety of users. Community gardens are acknowledged as valuable resources for

encouraging walking within urban areas (Bird, 2004; Kingsley et al., 2009), and may

therefore represent one such feature.

This value as a destination for walking may be attributed to the ability of a

community garden to provide a restorative environment, with opportunities to experience such environments likely to be one of the main reasons to visit a local park (Giles-Corti et al., 2005). We now turn to the issue of restoration.

\section{Restoration}


1 The literature identifies two separate theories that associate green spaces with restoring

2 healthy human functioning. The first is Attention Restoration Theory (Kaplan, 1995), which

3 posits that natural environments are more likely to engage effortless involuntary attention

4 than built environments. By engaging involuntary attention, the directed attention used for

5 more strenuous and tedious tasks is recharged, and this in turn leads to enhanced mental

6 capacity. The second is Stress Recover Theory (Ulrich et al., 1991), which suggests that

7 natural environments can alleviate the health risks associated with prolonged exposure to

8 stressful situations.

Community gardens, regardless of the activity undertaken therein, are effective forms of urban nature for providing restorative services. Gardening is acknowledged to be an activity that engages involuntary attention and leads to the restoration of direct attention (Kaplan, 1973; Kaplan \& Kaplan, 1989). Similarly, a survey on allotment gardening in the Netherlands found that 86 per cent of participants felt less stressed after visiting their garden (Van Den Berg et al., 2010). This was supported by a subsequent experimental study that identified greater decreases in the stress hormone cortisol after gardening compared with the control activity of reading (Van Den Berg \& Custers, 2011).

Even as passive destinations, community gardens can be effective restorative environments. Research by Nordh and colleagues (2009) found that even small green spaces can be valuable restorative resources; particularly when natural features such as flowers, trees and water are combined with intelligent spatial design to create the perception in the user of being away from the surrounding built environment. Furthermore, Grahn and Stigsdotter (2010) found that the sensory dimensions refuge and nature within urban green spaces were most related to stress restoration, while the dimension rich in species was more likely to restore attention. The potential for gardens to meet these criteria is supported by several studies that have specifically investigated the restorative value of gardens (Ottosson \& Grahn, 
1 2005; Tenngart Ivarsson \& Hagerhall, 2008; Adevi \& Mårtensson, 2013). Gardens created

2 within parks planned primarily for organised sport and characterised by playing fields and

3 built infrastructure may be particularly effective at providing restorative services.

If community gardens do indeed offer an attractive environment for restoration, they could also make a local park a more attractive destination for neighbourhood walking. This makes the inclusion of community gardens within under-utilised parks a multifunctional pathway for enhancing their ability to improve the health of local residents through the provision of ecosystem services. At the same time, they can also provide additional services at the community level.

\section{Community Services}

Urban green spaces can contribute services at the community level in various ways, including the facilitation of social interactions that create social ties and capital (Kazmierczak, 2013). While other urban spaces typically reinforce existing bonding relationships between individuals within similar social groups, parks and green spaces are more likely to facilitate superficial ties that can lead to the creation of new relationships between individuals from different social groups (de Vries, 2009). Such bridging interactions are necessary to create diverse social networks, which are more likely to generate positive health outcomes than a reliance on bonding relationships (Cattell et al., 2008).

Community gardens have great potential for bringing socially and culturally diverse individuals together. As one of the most common forms of recreation in Australia, gardening offers a context in which differences can be negotiated and greater understanding between different parties can be gained (Stocker \& Barnett, 1998). Many community gardens also actively facilitate community interactions through organised social events, allowing for valuable bonding and bridging relations to be created (Glover, 2003; Firth et al., 2011). In 
this way, community gardens can provide a similar community building function to other formal group activities such as sport, but for different and perhaps more varied demographic groups.

The physical properties of community gardens may also be a factor in their ability to facilitate social interactions. A study of public housing estates in Chicago, for example, found that social interactions are more likely within a public space with vegetation (Kuo et al., 1998). Thus, as well as increasing the likelihood of facilitating restoration and physical activity, the more natural environment provided by gardens could enhance the contribution of standardised park landscapes to community outcomes.

As well as facilitating social interactions, public participation in the planning process is considered essential for urban green spaces to act as community-building resources (Matsuoka \& Kaplan, 2008). Different individuals and cultures possess different relationships with nature, thus no green space will be valued equally or for the same qualities by all residents of a community (James et al., 2009). Rather than including only the assumptions of planning professionals, consultative approaches that engage the public early in the planning process are essential for creating green spaces that reflect the many and diverse needs of communities (Veal, 2008; Byrne et al., 2010).

Community gardens offer an opportunity for innovation in green space governance.

Community gardens may exhibit many different types of management, including by government, private organisations, health centres, schools, or an organised group of community gardeners (Lawson, 2005; Hou et al., 2009). Gardens created through civicdriven governance are most relevant here, since they are designed, built and managed by the residents who use them and can therefore better reflect user needs (Francis, 1989; Okvat \& Zautra, 2011; see Fig. 2). Creating such bottom-up gardens within existing public parkland effectively allows local authorities to transfer a significant component of the design and on- 
going management of this area of a park to the community, and potentially to encourage greater public participation in the broader park and green space systems.

Enabling public participation in the planning process has other positive effects. Direct involvement in the creation of a public space engenders a much deeper understanding between the user and the landscape (Francis, 1989). Indeed, simply knowing that the public has been involved in the planning of a space has been found to increase its value within the community, even for those who don't use it (Kaplan, 1980). To support this, research in Perth found that community gardens established by local residents were more valued and had a greater likelihood of generating a sense of community than were gardens established through top-down processes (Scagliotta, 2013).

Community gardens have been described 'more about community than they are about gardening' (Glover, 2003, p. 192). Indeed, community services have been the most commonly demonstrated benefits in recent community gardens research (Guitart et al., 2012).

Their potential for providing community services adds further weight to the argument for their integration into standardised park landscapes; however, so does their potential as unique spaces for environmental education.

(INSERT FIGURE 2 HERE PLEASE)

\section{Environmental Education}

The need for contact with natural environments has been forged over generations of human evolution (Kellert \& Wilson, 1993), and is acknowledged as essential to human health and wellbeing (Gullone, 2000). At odds with this however is the reality that people increasingly reside within urban areas where nature is either removed or hidden; leading to an environmental, generational amnesia dubbed the extinction-of-experience (Miller, 2005). As well as having direct adverse effects on human health and wellbeing, this detachment can 
1 have consequences for our ability to sustainably manage urban ecological systems (Miller,

2 2005). This phenomenon makes the provision of everyday opportunities to experience and

3 learn about nature a pressing planning challenge (Beatley, 2011).

Community gardens offer a unique resource for addressing the extinction of important

5 natural experiences. Gardening represents one of the most effective mechanisms for

6 ecological education in urban areas. Bendt et al. (2013) suggest that the most effective way to

7 re-engage urban citizens with natural processes is not through extracted collections of

8 ecological knowledge, but through forms of environmental learning that allow citizens to

9 practically engage with nature first hand. The act of gardening is one such activity: where

10 nature is experienced as an essential and active component rather than as a background element. It is also an activity that requires ongoing contact and commitment from participants as opposed to chance or casual experiences (Kaplan, 1973).

Community gardens may also provide suitable environments to passively experience urban nature as compared to more formal park landscapes. While local public green spaces are vital as a means of reconnecting residents with nature, Miller (2005) has suggested that formal parks and traditional playgrounds are unlikely to sufficiently engage young children, who are most in need of natural experiences. Instead, children are likely to benefit most from more natural and informal landscapes. Taking the example of Perth, standardised parks exhibit little innovation in providing children with local contact with nature. Natural environments typically take the form of complex remnant bushland that, whilst being highly bio-diverse, often provides little public access due to the dangers from snakes and other indigenous fauna, and/or as a measure to protect its ecological values. In contrast, community gardens may offer a relatively safe and accessible form of urban nature when compared with

24 the remnant bushland and even urban forests found in the green spaces of many cities (see 25 Fig. 3). 
2 public spaces where environmental agendas are actively promoted. Bendt and colleagues

3 (2013) found that community gardens with broad management regimes and lack of obstacles

4 for participation allowed for a higher degree of cultural diversity and associated

5 environmental learning outcomes as distinct from more closed forms of urban gardening. In

6 Perth for example, community gardens run by local residents have been used as venues for

7 the teaching of local environmental principles such as permaculture and the restoration of

8 local bushland (Stocker \& Barnett 1998).

Opportunities for active environmental education can produce tangible ecological outcomes. It is increasingly acknowledged that institutions such as Local Government, who typically manage these areas, lack the necessary resources, knowledge and organisation to successfully implement plans for the protection and on-going maintenance of green spaces with significant biodiversity values (Sandström et al., 2006). Instead, a civic turn can now be witnessed wherein the effective protection of urban green spaces for ecosystem services comes through active and organised civil social networks (Ernstson et al., 2008). Social networks created by community gardens that actively promote environmental agendas represent examples of this civic turn. In the example of Perth given above by Stocker and Barnett (1998), education in community gardens could complement initiatives such as 'Adopt a Bushland' that actively engages school children in the management of park landscapes with high ecological value. The location of these gardens within parks and adjacent to these ecological areas could increase this potential.

Historically, community gardens have been most popular during times of social crisis for their services of food production, beautification and neighbourhood activism (Lawson, 2005; Okvat \& Zautra, 2011). If the increasing extinction of natural experiences in urban areas and its subsequent affect on human and ecological health represents a new emerging 
1 crisis, this may partly explain the recent resurgence of interest in community gardens around

2 the world. Indeed, Okvat and Zautra (2011) suggest that one of the main benefits of the

3 current community gardening movement is its ability to foster a much deeper appreciation

4 and awareness of the relationship between human actions and the natural environment. This

5 can encourage an expanded awareness of environmental issues, civic activism and thereby

6 contribute to improved ecological outcomes. We suggest that their inclusion in formal green

$7 \quad$ space landscapes such as parks may be the next step in utilising this service.

8 (INSERT FIGURE 3 HERE PLEASE)

10 Discussion

11 In this paper we have explored the potential that integrating two distinct and largely independent forms of green space in urban areas - public parks and community gardens - has for providing ecosystem services to urban communities. However, discussion of the potential benefits needs to be balanced against the challenges that may arise from such integration. We briefly highlight three of the main challenges that might be faced: objections to community gardens as a use of public land; conflict between the bottom-up governance of community gardens with formal planning practice; and loss of community participation over time. space activity, or community gardens as desirable green space landscapes. Lawson (2005) provides a number of obstacles for the inclusion of community gardens into public land: the perception of gardening as an activity for personal gain which should therefore remain within the private domain; the merits of forgoing designed landscapes for gardening on often unproductive land; and the perception that many gardens are territorialised spaces with restricted access only to gardeners. 

overcome. Firstly, new community gardens should be created only in under-utilised parkland, and ideally located close to low socioeconomic or high-density developments where land for

4 private gardening may be limited. Secondly, we emphasise the importance of maintaining a

5 high degree of public access in these gardens, which is clearly fundamental to their inclusion

6 in public land. Lawson (2005) suggests the perception of public accessibility can be enhanced

$7 \quad$ through clearly posting opening hours, as well as by regularly hosting organised

8 neighbourhood events. Such gardens have been described as 'public-access community

9 (PAC)' gardens, which combine the green area user management of allotment gardens with 10 the public accessibility of parks to create communal green spaces collectively managed by 11 civil society (Bendt et al., 2013). It is these specific types of community gardens that are likely to have the most success in providing ecosystem services when included within public parkland. emphasised that we are not suggesting that new community gardens be fully formalised into public park landscapes and planning processes. As we have argued, much of the value of community gardens is that they operate largely through bottom-up processes that exist outside of formal planning systems. Thus attempts to fully formalise their creation and management are in many ways antithetical to their value as green spaces, and require that the gardeners retain some degree of autonomy. Maintaining such autonomy will inevitably bring challenges from a planning perspective, with modes of community garden governance often seeming incompatible with the rigid top-down approach typically applied to other public spaces (Lawson, 2004 \& 2005; Hou et al., 2009).

Given that some degree of conflict between top-down and bottom-up governance roles is inevitable, strategies for negotiating this conflict are essential if a community garden 
1 is to be successful and sustainable. Stocker and Barnett (1998) found such tension in their

2 case study garden, and suggest that the specific roles of each group should be determined at

3 the start of the garden's life. Clearly establishing the degree of autonomy that is permitted for

4 local residents, within the garden and the whole park, would seem to be an essential first step.

5 Another strategy is to reinforce the benefits that promoting community ownership of

6 public land has for formal planning institutions. Research by Rosol (2010) on community

7 gardening in Berlin found a gradual acceptance of civic-governed green spaces, with original

8 antagonism evolving into support and even initiation. Such engagement stemmed from

9 acknowledgment of the numerous benefits of volunteer-based community gardening projects,

10 including improved neighbourhood appearance and stability. Perhaps the most fundamental

11 benefits were economic, as this allowed for a reduced reliance on public expenditure by

12 transferring more responsibility to the community (Rosol, 2010). Rather than being

13 antithetical to the aims of formal planning, this evidence suggests that community gardening

14 can play a valuable complementary role to these institutions.

That said, such benefits rely on sustained and prolonged involvement from the local

community. In a subsequent paper, Rosol (2012) noted the limitations of community gardens

in passing responsibilities for green space management on to community volunteers, and

observed that long-term engagement often remains as 'wishful thinking' (p. 246). In such

cases, responsibility for the garden is likely to fall back on the formal institutions.

Alternatively, gardens could fall into disrepair, which has the potential to reduce the value of the surrounding parkland. Aside from ensuring sufficient community support before creating a new garden, on-going strategies for addressing a loss of resident interest could include community outreach and education initiatives (Lawson, 2004).

\section{Conclusion}


1 While the concepts of community gardens and volunteer green space governance may still be

2 foreign to many urban residents, this paper demonstrates the range of benefits that could

3 potentially be provided if this movement were to be more widely promoted and supported.

4 With this in mind, we conclude with a call for more research into existing practice of

5 integrating community garden and formal green space planning, including community garden

6 creation within public parkland. Ultimately, the extent of the challenges faced and the success

7 of the strategies aimed at overcoming them will only become clear through more detailed

8 case studies of community gardens created within new and existing public parkland.

9 Additionally, if such research is able to demonstrate that community gardens can

10 significantly enhance the ability of formal public green spaces to provide ecosystem services

11 to communities, it provides a basis for more easily overcoming the potential objections of

12 both local residents and planning authorities. Thus, building this evidence base represents the most useful strategy for addressing any emergent challenges and obstacles.

Notable examples and research into the integration between formal planning and community gardening already exist, such as that detailing the success of Seattle's P-Patch

16 Program (Hou et al., 2009). Examples of community gardens situated within public parks

17 also occur in many Canadian cities, including Toronto and Vancouver. Opportunistic examples can also be found in Perth (see Fig. 4). We hope that this paper will stimulate interest in future research into the benefits of creating community gardens within new and existing parkland, while providing a potential theoretical framework of ecosystem services to guide detailed case studies of such initiatives. We also anticipate that the resultant insights will ultimately become a catalyst for greater integration between formal green space planning and the emerging community gardening movement. 


\section{Acknowledgements}

2 This research was supported by the members of the Writing Factory: an initiative of Curtin

3 University's Centre for Sport and Recreation Research. We are also grateful to the feedback

4 provided by the two anonymous reviewers. All photographs taken by authors.

5

6 


\section{References}

2 Adevi, A. A., \& Mårtensson, F., 2013. Stress rehabilitation through garden therapy: The

5 Beatley, T., 2011. Biophilic cities. Island Press, Washington DC.

6 Bendt, P., Barthel, S., \& Colding, J., 2013. Civic greening and environmental learning in 7 public-access community gardens in Berlin. Landscape and Urban Planning, 109(1), 18-30.

Bird, W., 2004. Natural fit: Can green space and biodiversity increase levels of physical activity? Report for the Royal Society for the Protection of Birds.

Bolund, P., \& Hunhammar, S., 1999. Ecosystem services in urban areas. Ecological Economics, 29, 293-301.

Byrne, J., Sipe, N., \& Searle, G., 2010. Green around the gills? The challenge of density for urban greenspace planning in SEQ. Australian Planner, 47(3), 162-177.

Cameron, R. W. F., Blanusa, T., Taylor, J. E., Salisbury, A., Halstead, A. J., Henricot, B., \& Thompson, K. (2012). The domestic garden - its contribution to urban green infrastructure. Urban Forestry \& Urban Greening, 11(2), 129-137.

Carter, M., 2011. Public open space planning in Western Australia: New residential developments. Position paper (revised). Parks and Leisure Australia (WA Region), Perth, Western Australia.

Cattell, V., Dines, N., Gesler, W., \& Curtis, S., 2008. Mingling, observing, and lingering: Everyday public spaces and their implications for well-being and social relations. Health \& Place, 14(3), 544-561. 
1 Costanza, R., d'Arge, R., De Groot, R., Farber, S., Grasso, M., Hannon, B., Limburg, K., Naeem, S., O’Neill, R. and Paruelo, J., 1998. The value of the world's ecosystem services and natural capital. Ecological Economics, 25(1), 3-15.

Cranz, G., \& Boland, M., 2004. Defining the sustainable park: A fifth model for urban parks. Landscape Journal, 23(2), 102-120.

De Vries, S., 2009. Nearby nature and human health: Looking at mechanisms and their implications. In: C. W. Thompson, P. Aspinall, \& S. Bell (Eds.), Innovative approaches to researching landscape and health. Routledge, Oxon, pp 77-96.

Dunn, A. D., 2010. Siting green infrastructure: Legal and policy solutions to alleviate urban poverty and promote healthy communities. Paper 559, Pace Law Faculty Publications.

Elmqvist, T., Colding, J., Barthel, S., Borgstrom, S., Duit, A., Lundberg, J., Andersson, E., Ahrne, K., Ernstson, H., Folke, C. and Bengtsson, J., 2004. The dynamics of socialecological systems in urban landscapes - Stockholm and the national urban park, Sweden. Urban Biosphere and Society: Partnership of Cities, 1023, 308-322.

Ernstson, H., Sorlin, S., \& Elmqvist, T., 2008. Social movements and ecosystem services the role of social network structure in protecting and managing urban green areas in Stockholm. Ecology and Society, 13(2), 39.

Evers, A. \& Hodgson, N., 2011. Food choices and local food access among Perth's community gardeners. Local Environment, 16(6), 585-602.

Firth, C., Maye, D., \& Pearson, D., 2011. Developing "community" in community gardens. Local Environment, 16(6), 555-568.

Francis, M., 1989. The urban garden as public space. Places, 6(1), 52-59.

Freestone, R., \& Nichols, D., 2004. Realising new leisure opportunities for old urban parks: The internal reserve in Australia. Landscape and Urban Planning, 68(1), 109-120. 
1 Giles-Corti, B., Broomhall, M. H., Knuiman, M., Collins, C., Douglas, K., Ng, K., Lange, A. and Donovan, R. J., 2005. Increasing walking: How important is distance to, attractiveness, and size of public open space? American Journal of Preventive Medicine, 28(2, Supplement 2), 169-176.

Glover, T. D., 2003. The story of the Queen Anne memorial garden: Resisting a dominant cultural narrative. Journal of Leisure Research, 35(2), 190-212.

Grahn, P., \& Stigsdotter, U. K., 2010. The relation between perceived sensory dimensions of urban green space and stress restoration. Landscape and Urban Planning, 94(3-4), 264-275.

Grose, M. J., 2009. Changing relationships in public open space and private open space in suburbs in south-western Australia. Landscape and Urban Planning, 92(1), 53-63.

Guitart, D., Pickering, C., \& Byrne, J., 2012. Past results and future directions in urban community gardens research. Urban Forestry \& Urban Greening, 11(4), 364-373.

Gullone, E., 2000. The biophilia hypothesis and life in the 21st century: Increasing mental health or increasing pathology? Journal of Happiness Studies, 1(3), 293-322.

Harnik, P., 2010. Urban green: Innovative parks for resurgent cities. Island Press, Washington.

Hou, J., Johnson, J. M., \& Lawson, L. J., 2009. Greening cities, growing communities: Learning from Seattle's urban community gardens. University of Washington Press, Seattle, WA.

Husqvarna Group, 2012. Husqvarna Global Garden Report 2012. Retrieved March 31st, 2104 from http://husqvarnagroup.com/afw/files/press/husqvarna/Husqvarna_Global_Garden_Re port_2012.pdf 
1 James, P., Tzoulas, K., Adams, M. D., Barber, A., Box, J., Breuste, J., Elmqvist, T., Frith, M., Gordon, C., Greening, K.L., Handley, J., Haworth, S., Kazmierczak, A.E., Johnston, M., Korpela, K., Moretti, M., Niemela, J., Pauleit, S., Roe, M.H., Sadler, J.P. and Thompson, C. W., 2009. Towards an integrated understanding of green spaces in the European built environment. Urban Forestry \& Urban Greening, 8, 65-75.

6 Kaplan, R., 1973. Some psychological benefits of gardening. Environment and Behavior, 7 $5(2), 145-162$.

Kaplan, R., 1980. Citizen participation in the design and evaluation of a park. Environment and Behavior, 12(4), 494-507.

Kaplan, R., \& Kaplan, S., 1989. The experience of nature: A psychological perspective. Cambridge University Press, New York.

Kaplan, S., 1995. The restorative benefits of nature: Toward an integrative framework. Journal of Environmental Psychology, 15, 169-182.

Kazmierczak, A., 2013. The contribution of local parks to neighbourhood social ties. Landscape and Urban Planning, 109(1), 31-44.

Kellert, S. R., \& Wilson, E. O., 1993. The biophilia hypothesis. Island Press, Washington DC.

Kingsley, J., Townsend, M., \& Henderson-Wilson, C., 2009. Cultivating health and wellbeing: Members' perceptions of the health benefits of a Port Melbourne community garden. Leisure Studies, 28(2), 207-219.

Kuo, F., Sullivan, W., Coley, R., \& Brunson, L., 1998. Fertile ground for community: InnerCity neighborhood common spaces. American Journal of Community Psychology, 26(6), 823-851.

Lachowycz, K., \& Jones, A. P., 2011. Greenspace and obesity: A systematic review of the evidence. Obesity Reviews, 12(5), e183-e189. 
1 Lawson, L., 2004. The planner in the garden: A historical view into the relationship between planning and community gardens. Journal of Planning History, 3(2), 151-176.

3 Lawson, L., 2005. City bountiful: A century of community gardening in America. University of California Press, Berkeley.

Matsuoka, R. H., \& Kaplan, R., 2008. People needs in the urban landscape: Analysis of landscape and urban planning contributions. Landscape and Urban Planning, 84(1), 7 19.

Millennium Ecosystem Assessment, 2005. Ecosystems and human health: Synthesis. Island Press, Washington, DC.

Miller, J. R., 2005. Biodiversity conservation and the extinction of experience. Trends in Ecology \& Evolution, 20(8), 430-434.

Niemelä, J., Saarela, S. -R., Söderman, T., Kopperoinen, L., Yli-Pelkonen, V., Väre, S., \& Kotze, D., 2010. Using the ecosystem services approach for better planning and conservation of urban green spaces: A Finland case study. Biodiversity and Conservation, 19(11), 3225-3243.

Nordh, H., Hartig, T., Hagerhall, C. M., \& Fry, G., 2009. Components of small urban parks that predict the possibility for restoration. Urban Forestry \& Urban Greening, 8(4), 225-235.

Okvat, H., \& Zautra, A., 2011. Community gardening: A parsimonious path to individual, community, and environmental resilience. American Journal of Community Psychology, 47(3), 374-387.

Ottosson, J., \& Grahn, P., 2005. A comparison of leisure time spent in a garden with leisure time spent indoors: On measures of restoration in residents in geriatric care. Landscape Research, 30(1), 23-55. 
1 Rosol, M., 2010. Public participation in post-Fordist urban green space governance: The case of community gardens in Berlin. International Journal of Urban and Regional Research, 34(3), 548-563.

Rosol, M. 2012. Community volunteering as neoliberal strategy? Green space production in Berlin. Antipode, 44(1), 239-257.

Sandström, U. G., Angelstam, P., \& Khakee, A., 2006. Urban comprehensive planning identifying barriers for the maintenance of functional habitat networks. Landscape and Urban Planning, 75(1-2), 43-57.

Scagliotta, N., 2013. Understanding what public open space means to people in Perth, Western Australia: Exploring sense of place using Causal Layered Analysis. Honours Thesis. Curtin University, Bentley, Western Australia.

Stephenson, G., \& Hepburn, J. A., 1955. Plan for the metropolitan region Perth and Fremantle Western Australia. Government Printing Office, Perth.

Stocker, L., \& Barnett, K., 1998. The significance and praxis of community-based sustainability projects: Community gardens in Western Australia. Local Environment, 3(2), 179-189.

Sugiyama, T., Francis, J., Middleton, N. J., Owen, N., \& Giles-Corti, B., 2010. Associations between recreational walking and attractiveness, size, and proximity of neighborhood open spaces. American Journal of Public Health, 100(9), 1752-1757.

Swanwick, C., Dunnett, N., \& Woolley, H., 2003. Nature, role and value of green space in towns and cities: An overview. Built Environment, 29(2), 94-106.

Tenngart Ivarsson, C., \& Hagerhall, C. M., 2008. The perceived restorativeness of gardens assessing the restorativeness of a mixed built and natural scene type. Urban Forestry \& Urban Greening, 7(2), 107-118. 
1 Tzoulas, K., Korpela, K., Venn, S., Yli-Pelkonen, V., Kazmierczac, A., Niemela, J., \& James, P., 2007. Promoting ecosystem and human health in urban areas using green infrastructure: A literature review. Landscape and Urban Planning, 81(3), 167-178.

Ulrich, R. S., Simons, R. F., Losito, B. D., Fiorito, E., Miles, M. A., \& Zelson, M., 1991. Stress recovery during exposure to natural and urban environments. Journal of Environmental Psychology, 11(3), 201-230.

Van Den Berg, A. E., \& Custers, M. H., 2011. Gardening promotes neuroendocrine and affective restoration from stress. Journal of Health Psychology, 16(1), 3-11.

Van Den Berg, A. E., Van Winsum-Westra, M., De Vries, S., \& Van Dillen, S. M., 2010. Allotment gardening and health: A comparative survey among allotment gardeners and their neighbors without an allotment. Environmental Health: A Global Access Science Source, 9(1), 74.

Veal, A. J., 2008. Alternatives to standards: A review of leisure planning guidelines. University of Technology, Sydney.

Western Australian Planning Commission, 2010. Directions 2031 and beyond: Metropolitan planning beyond the horizon. Perth, Western Australia. 


\section{Figures}

2 Figure 1: Aerial photo of a typical standardised public park in Perth. The park is dominated by playing fields and built infrastructure, leaving few opportunities for other forms of recreation and space for vegetation (Source: Google Earth)

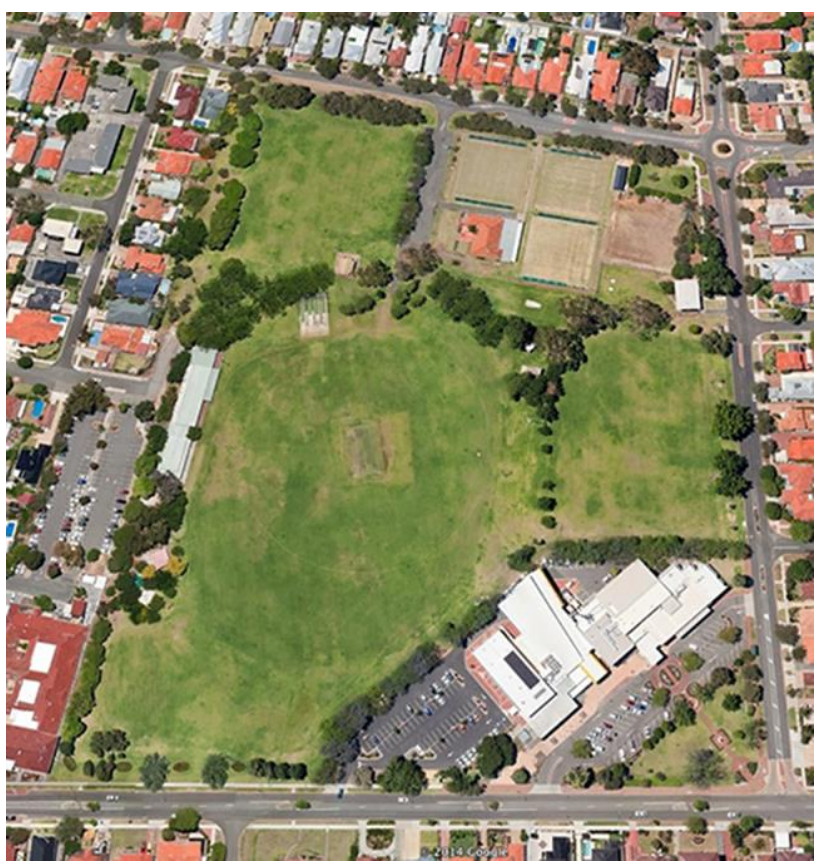

6 
1 Figure 2: Butler Community Garden contains a wood fired pizza oven to encourage formal and informal social gatherings.

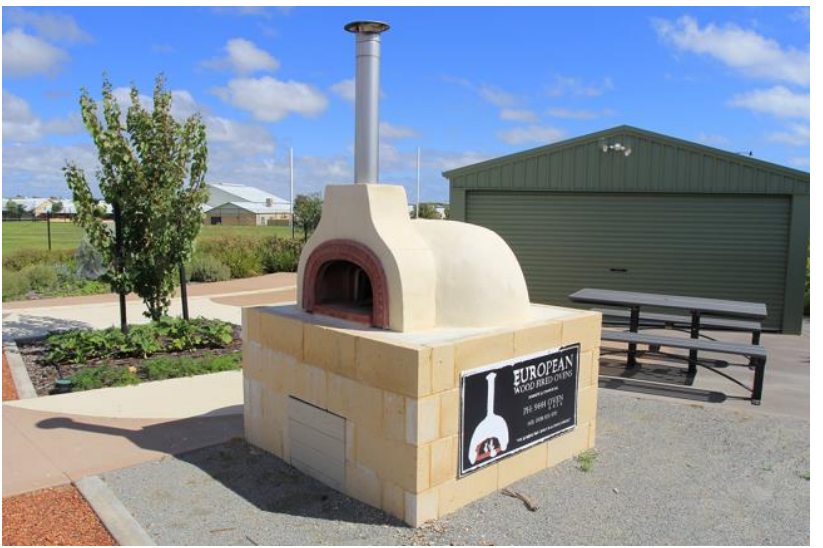


1 Figure 3: Community gardens in Perth offer safe yet hands-on opportunities to experience

2 urban nature.

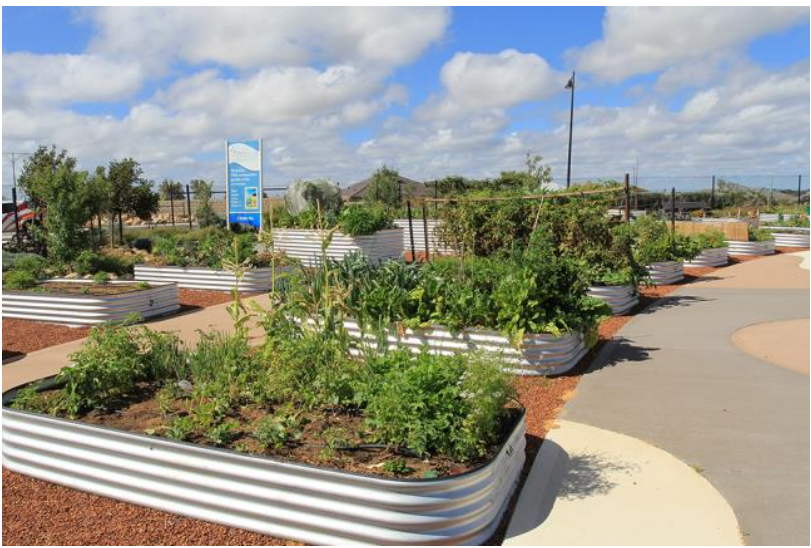

4 
1 Figure 4: Neil McDougall Park is an example of the successful integration of a community

2 garden into an existing public park.

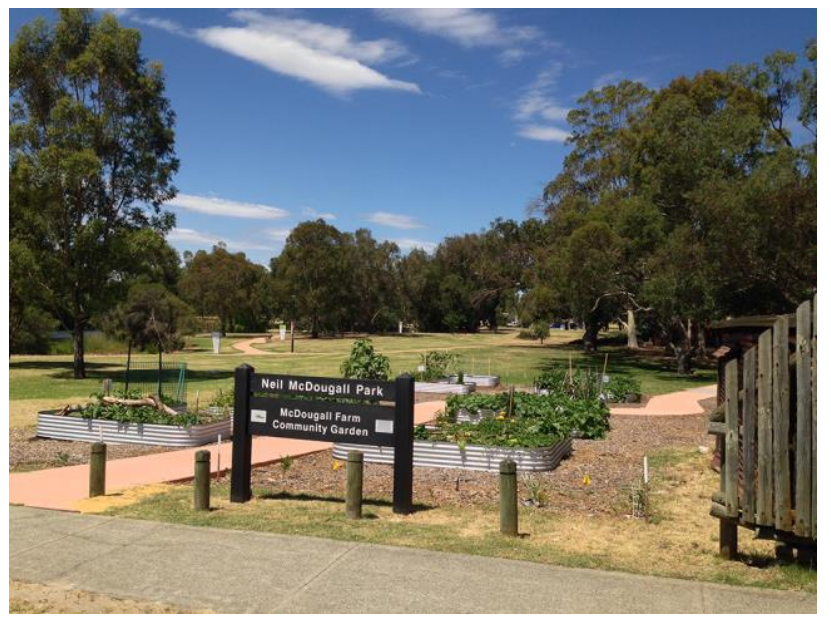

